\title{
Pemetaan Penyebaran Titik Rawan Kriminalitas di Kota Bandung Menggunakan Leaflet Javascript Library Berbasis Website
}

\author{
Rio Ariswendi ${ }^{1}$, Chairuddin ${ }^{2}$ \\ ${ }^{1}$ Program Studi Sistem Informasi, ${ }^{2}$ Program Studi Teknik Informatika \\ ${ }^{1,2}$ STMIK Indonesia Mandiri Bandung, Indonesia \\ Email : rioariswendi97@gmail.com ${ }^{1}$,ch.ruddin@gmail.com ${ }^{2}$
}

\begin{abstract}
ABSTRAK
Kota Bandung sebagai Ibu kota Propinsi Jawa Barat menjadi pusat perekonomian yang akan berdampak besar terhadap peningkatan pergerakan dan mobilitas. Bandung juga memiliki masalah yang pada umumnya dimiliki kota besar lainnya, yaitu kriminal. Kota Bandung merupakan salah satu kota di Jawa Barat yang memiliki jumlah kasus kriminal yang cukup tinggi dengan banyak kasus kriminal yang terjadi di sekitar jalan raya. Salah satu solusi yang dapat dilakukan untuk mengurangi kasus kriminal di jalan raya adalah dengan memberikan informasi mengenai daerah mana saja yang rawan kriminal yang terjadi sebelumnya. Titik wilayah merupakan salah satu cara untuk menyajikan informasi tersebut. Dalam pendataan dan kolaborasi dengan Leaflet.Js sebagai perpustakaan yang digunakan untuk pembuatan peta WEBGIS, sehingga pengguna dapat dengan mudah mengaksesnya dimanapun dan kapanpun sebagai informasi tentang penyebaran titik rawan kriminalitas di kota Bandung.
\end{abstract}

Kata kunci: Kriminal, Pemetaan, leafleatjs, Sistem Informasi Geografis

\section{ABSTRACT}

Bandung as the capital of West Java is the center of the economy which will have a major impact on increasing movement and mobility. Bandung also has problems that other big cities generally have, namely crime. Bandung City is one of the cities in West Java which has a high number of criminal cases with many criminal cases occurring around the highway. One solution that can be done to reduce criminal cases on the highway is to provide information about which areas are prone to previous crimes. An area point is one way of presenting this information. In data collection and collaboration with Leaflet.Js as the library used for making WEBGIS maps, so users can easily access it anywhere and anytime as information about the spread of crimeprone points in the city of Bandung.

Keywords: Crime, Mapping, Leafleatjs, Geographical Information System

\section{PENDAHULUAN}

Teknologi Sistem Informasi Geografis (GIS) telah berkembang pesat. GIS dibuat dengan menggunakan informasi yang berasal dari pengolahan sejumlah data, yaitu data geografis atau data yang berkaitan dengan posisi obyek di permukaan bumi. GIS dapat disajikan dalam bentuk aplikasi desktop maupun aplikasi berbasis web. GIS juga dapat 
memberikan penjelasan tentang suatu peristiwa, membuat peramalan kejadian, dan perencanaan strategis lainnya serta dapat membantu menganalisis permasalahan umum seperti masalah ekonomi, penduduk, sosial pemerintahan, pertahanan serta masalah kriminal yang terjadi disuatu wilayah tertentu.

Dari sudut pandang ilmu geografi, kriminalitas memiliki dimensi ruang, dimana suatu tindak kriminal memiliki tempat kejadian dengan lokasi geografis tertentu (Ambarwati \& Johan, 2016). Pemetaan kriminal dapat berperan penting dalam mencegah dan mengurangi tindak kriminal. Salah satunya dengan mengidentifikasi titik-titik daerah rawan kriminal, penyebarannya serta seberapa sering tindakan kriminal terjadi pada daerah-daerah rawan tersebut agar dapat dilakukan tindakan pencegahan yang sesuai. Informasi mengenai daerah-daerah rawan kriminal tersebut dapat dengan mudah disampaikan kepada masyarakat umum apabila terdapat sistem informasi yang mudah diakses(Nelasari et al., 2019).

Dengan adanya sistem informasi yang dapat memetakan penyebaran titik daerah rawan tindak kriminal dapat memberikan informasi wilayah yang sering terjadi tindak kriminal.

Berdasarkan pada penjelasan latar belakang yang telah disebutkan sebelumnya, maka penulis tertarik untuk melakukan penelitian berjudul "Pemetaan Penyebaran Titik Rawan Kriminalitas Di Kota Bandung Menggunakan Leaflet Javascript Library Berbasis Website".

\section{METODE PENELITIAN}

\subsection{Metode Pengumpulan Data}

Adapun metode pengumpulan data yang dilakukan untuk mendapatkan data-data dan referensi yang dibutuhkan dalam menyusun penelitian ini, meliputi:

\section{Observasi}

Observasi dilakukan secara langsung pada Polres Kota Bandung untuk mengetahui proses bisnis dan permasalahan yang terjadi saat ini. Hasil dari observasi yang dilakukan yaitu mengamati dan mempelajari dokumen pencatatan kejadian kriminal kepolisian, laporan kepolisian digunakan untuk mencatat kejadian kriminal. Hasil observasi yang sudah dilakukan, akan digunakan untuk perancangan sistem. data lokasi yang diperoleh akan digunakan sebagai titik point dalam menentukan kejadian 
lokasi tindak kriminal.

2. Wawancara

Proses wawancara dilakukan dengan cara mengajukan beberapa pertanyaan kepada anggota polisi yang bertugas di Polres Kota Bandung bagian SPKT, tujuan dari wawancara untuk mendapatkan dan menggali informasi dan data-data yang dibutuhkan untuk kebutuhan sistem yang akan dibuat. Hasil dari wawancara adalah pada Polres Kota Bandung belum mempunyai sistem informasi yang dapat menampilkan data dan informasi secara real time untuk masyarakat.

\section{Studi Kepustakaan}

Dilakukan dengan cara membaca dan mempelajari buku-buku, referensi yang mendukung dengan topik yang akan dibahas dalam penyusunan penelitian ini, selain itu penulis juga mengumpulkan data dari situs-situs internet yang berhubungan dengan penelitian ini. Dalam penelitian ini dibutuhkan data kriminal di kota bandung untuk membuat titik lokasi rawan kriminal. Data peta wilayah kota bandung yang berbentuk file GeoJson diunduh dari website Data SWK (Sub Wilayah Kota) Bandung (Portal Data Kota Bandung, 2015) .

\subsection{Metode pengenbangan sistem}

Penelitian ini menggunakan metode pengembangan (SDLC) dengan Model Waterfall. Model ini melakukan pendekatan secara sistematis dan berurutan. Metode Waterfall mempunyai tahapan-tahapan yang digambarkan pada Gambar 1

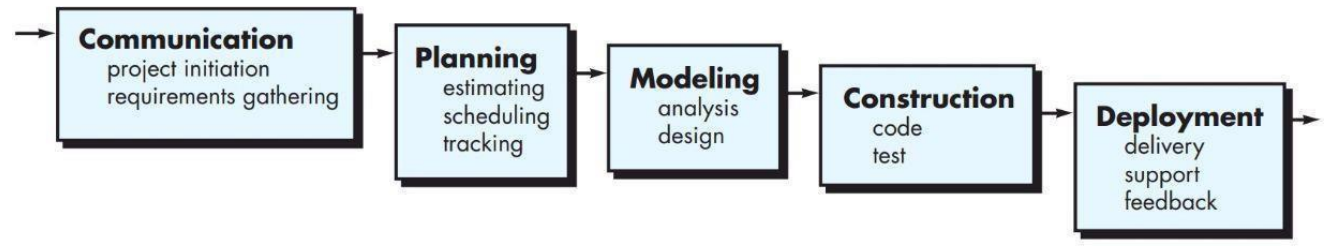

Gambar 1: Model Waterfall (R.S.Pressman, 2015)

Tahapan utama dalam siklus klasik/ model waterfall rekayasa perangkat lunak menurut (R.S.Pressm an, 2015) adalah sebagai berikut :

\section{Requirement Analysis and Definition}

Sebelum memulai pekerjaan yang bersifat teknis, sangat diperlukan adanya 
komunikasi dengan customer demi memahami dan mencapai tujuan yang ingin dicapai. Hasil dari komunikasi tersebut adalah inisialisasi proyek, seperti menganalisis permasalahan yang dihadapi dan mengumpulkan data - data yang diperlukan, serta membantu mendefinisikan fitur dan fungsi perangkat kunak .

Pengumpulan data - data tambahan bisa juga daimbil dari jurnal, artikel dan internet. Dalam tahap penelitian ini akan dilakukan studi lapangan dan metode pustaka untuk mengumpulkan data, informasi, permasalahan, dan kebutuhan untuk sistem yang akan dibangun.

\section{Planning (Estimating, Schedulling, Tracking)}

Tahap berikutnya adalah tahapan perencanaan yang menjelaskan tentang estimasi tugas - tugas teknis yang akan dilakukan, resiko - resiko yang dapat terjadi, sumber daya yang diperlukan dalam membuat sistem, produk kerja yang ingin dihasilkan, penjadwalan kerja yang akan dilaksanakan, dan tracking proses pengerjaan sistem.

Dalan tahap penelitian ini akan dilakukan penjadwalan pengerjaan penelitian, identifikasi resiko yang akan muncul dan mencoba mencari solusinya.

\section{Modelling (Analysis \& Design)}

Tahapan ini adalah tahap perancangan dan pemodelan arsitektur sistem yang berfokus pada perancangan struktur data, arsitektur perangkat lunak, tampilan antarmuka, dan algoritma program. Tujuannya untuk lebih memahami masalah serta bagaimana menyelesaikannya, dan untuk mengetahui gambaran besar dari apa yangakan dijelaskan .

Analisis disini dilakukan dengan pemodelan Data Flow Diagram (DFD). Dalam tahap penelitian ini akan dibuat pemodelan analisis dan rancangan tampilan antarmuka untuk memberikan gambaran besar sistem yang akan dibangun.

\section{Construction (Code \& Test)}

Tahapan construction ini merupakan proses penerjemahan bentuk desain menjadi kode atau bentuk bahasa yang dapat dibaca oleh mesin. Setelah pengkodean selesai, dilakukan pengujian terhadap sistem dan juga kode yang sudah dibuat. Tujuannya untuk menemukan kesalahan yang mungkin terjadi untuk nantinya diperbaiki .

Dalam tahap penelitian ini akan dilakukan pengkodean yang menggunakan bahasa pemrograman PHP dan pengujian hasil sistem dengan menggunakan metode blackbox testing. 


\section{Deployment (Delivery, Support, Feedback)}

Tahapan deployment merupakan tahapan implementasi perangkat lunak kepada customer, pemeliharaan perangkat lunak secara berkala, perbaikan perangkat lunak, evaluasi perangkat lunak, dan pengembangan perangkat lunak berdasarkan umpan balik yang diberikan agar sistem dapat tetap berjalan dan berkembang sesuai dengan fungsinya.

\section{HASIL DAN PEMBAHASAN}

Kebutuhan akan sistem informasi bagi masyarakat yang dapat memperlihatkan sebaran titik rawan kriminalitas akan menjadi salah satu alternatif untuk meminimalisasi tindak kejahatan yang terjadi, serta masyarakat dapat lebih waspada bila harus melewati kawasan rawan tindak kriminalitas. Untuk itu sistem informasi geografis Penyebaran Titik Rawan Kriminalitas, hadir untuk menjawab persoalan kemasyarakatan dalam hal meminimalisasi tindak kejahatan di kota Bandung.

\subsection{Analisis Kebutuhan}

Rancangan sistem yang dibangun memerlukan data kejadian kriminalitas yang di dapat dari polres Kota Bandung dan koordinat titik rawan nantinya di dapat dari GoggleMaps. Setelah mendapatkan data selanjutnya melakukan identifikasi kebutuhan perangkat keras, perangkat lunak dan olah pikir.

Terdapat tiga analisis kebutuhan dalam membangun sistem informasi geografis penyebaran titik rawan kriminalitan di kota Bandung yaitu:

1. Kebutuhan fungsional yang meliputi dua kategori(Andrianto \& Jazman, 2018) :

a. Kebutuhan fungsional admin. Admin disini bertugas untuk mengelola data kecamatan dan titik rawan kriminal. Sebelum menambahkan, mengubah atau menghapus data sekolah admin perlu melakukan login sebelumnya.

b. Kebutuhan fungsional user. User atau pengunjung website dapat melihat peta pesebaran titik rawan kriminal, mencari kata kunci yang diinginkan, dan melihat Kota Bandung.

2. Kebutuhan Hardware maka memerlukan perangkat sebagai berikut: laptop (AMD A9-9420 RADEON R5, RAM 4GB DDR4, HDD 500GB,Layar $1366 \times 768(64 \mathrm{bit} / 3.6 \mathrm{gHz})$.

3. Kebutuhan Software maka menggunakan rancang bangun sebuah sistem WebGIS 
dengan menggunakan bahasa pemrogramman PHP, MySql sebagai Database Manajemen Sistem (DBMS). MySql memiliki beberapa kelebihan seperti tidak berbayar, kecepatan proses yang baik dan mudah digunakan. Untuk mengelola bagian frontend penulis menggunakan HTML, CSS serta JavaScript dan menggunakan library Leaflet untuk pembuatan peta. Dalam menjalankan sebuah website diperlukan adanya XAMPP v3.2.2 berguna dalam mengelola website(Abdulloh, 2016).

\subsection{Desain Sistem}

Desain sistem dilakukan untuk merancang user interface dan proses yang akan dilakukan oleh sisten, proses perancangan dalam penelitian ini menggunakan DFD (DATA FLOW DIAGRAM) dengan maksud memperlihatkan kesederhanaan pola pikir dari proses yang dilakukan sistem(Kristanto, 2008).

\section{Diagram Konteks}

Diagram konteks menggambarkan keseluruhan sistem meliputi seluruh input ke sistem atau output dari system. Diagram kontek pada penelitian ini melibatkan dua entitas yang berfungsi sebagai sumber data atau tujuan data yaitu admin dan user, seperti terlihat pada gambar 2 .

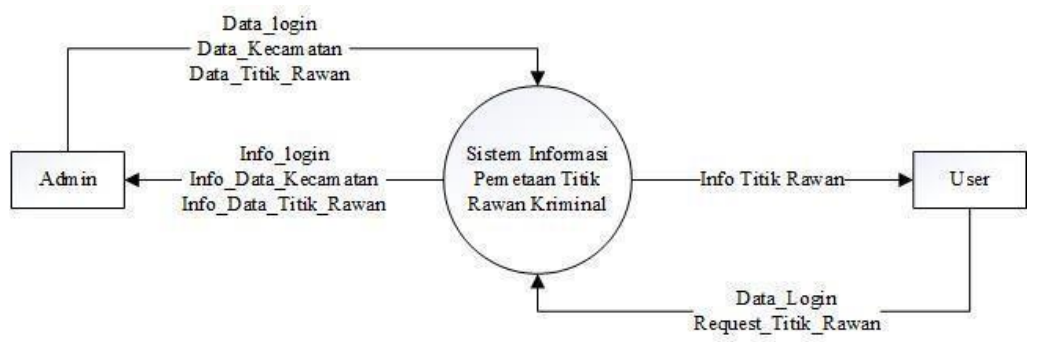

Gambar 2: Diagram konteks

proses pengolahan data proses ini menangani semua akses yang berhubungan dengan peta yang di tampilkan di website. Fungsi entitas admin dapat menambahkan ataupun mengurangi titik lokasi rawan sesuai keperluan, sedangkan user dapat melakukan login dan hanya dapat melihat peta titik rawan Kota Bandung.. 


\section{Data Flow Diagram (DFD)}

Penjelasan detil proses dalam mengelola data dari entitas sumber dan memberikan informasi ke entitas tujuan.

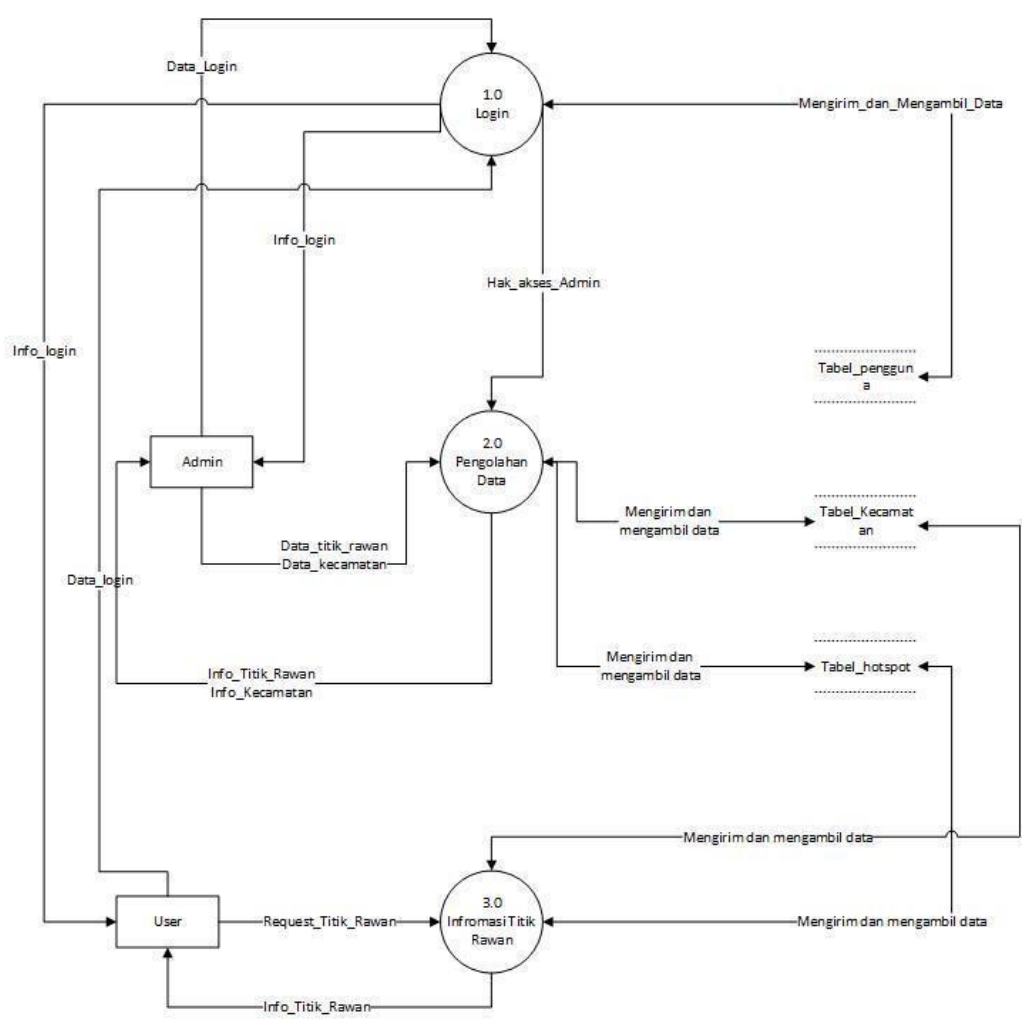

Gambar 3: DFD LEVEL 1

Data flow diagram pada gambar 3, memuat proses inti yang ada di dalam sistem , proses yang dilakukan di antaranya adalah proses login untuk pengecekan user atau admin. Admin mendapat hak akses pada sistem, setiap admin melakukan login, data yang akan di periksa dengan data yang ada di basis data. Apabila cocok admin akan mendapat hak akses pada sistem dan apabila tidak cocok maka sistem akan menolak admin masuk .

Sedangkan user hanya dapat melihat informasi titik rawan saja. Setelah proses login lanjut ke proses pengolahan data . proses ini menangani semua akses yang behubungan dengan peta yang di tampilkan di website. Admin dapat menambahkan ataupun mengurangi titik lokasi rawan sesuai keperluan. Terakhir adalah proses informasi, proses ini menampilkan halaman web atau peta kepada admin dan user. 


\section{Entity Relationship Diagram (ERD)}

Entity Relationship Diagram (ERD) merupakan suatu model untuk menjelaskan

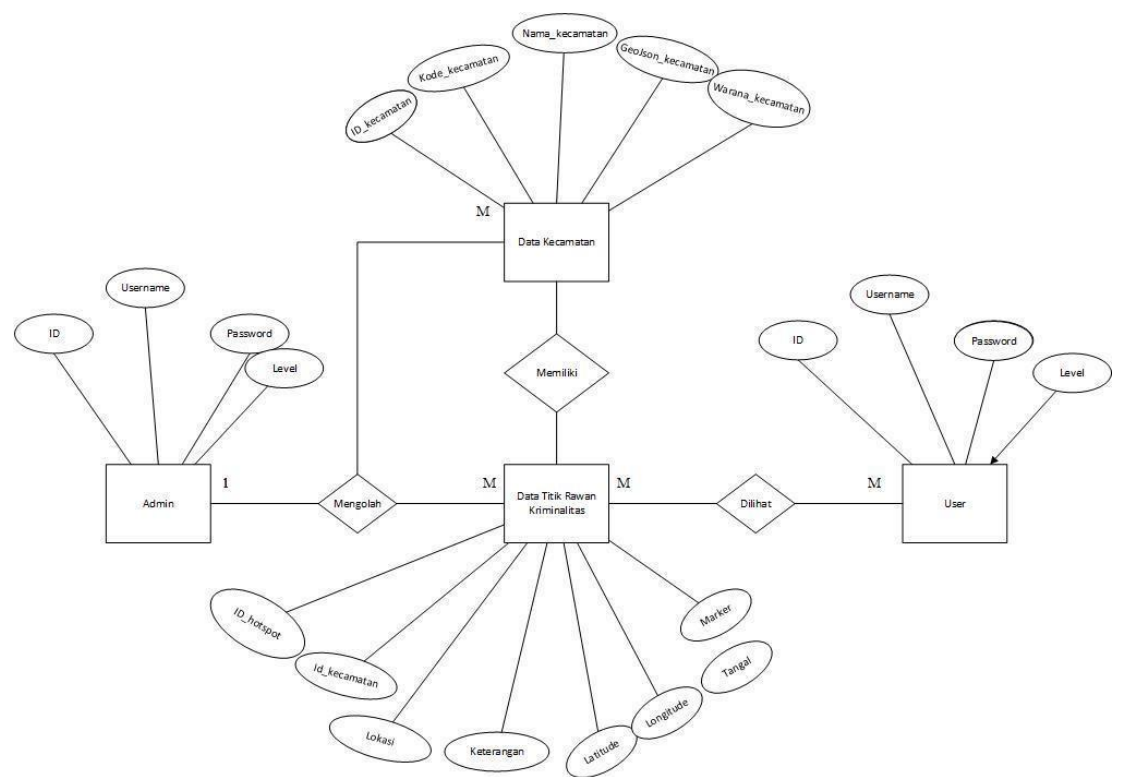

hubungan antar data dalam basis data berdasarkan objek-objek dasar data yang mempunyai hubungan antar relasi. ERD untuk memodelkan struktur data dan hubungan antar data, untuk menggambarkannya digunakan beberapa notasi. Berikut adalah perancangan database menggunakan ERD(Indrajani, 2015).

Gambar 4: Perancangan Database menggunakan ERD

\section{Rancangan antarmuka sistem}

Rancangan antarmuka menggambarkan bagaimana tampilan acuan interaksi antara user dengan sistem yang dibangun, sehingga menjadikan sistem dapat beroperasi sesuai dengan keinginan user. Berikut adalah perancangan terhadap antarmuka system :

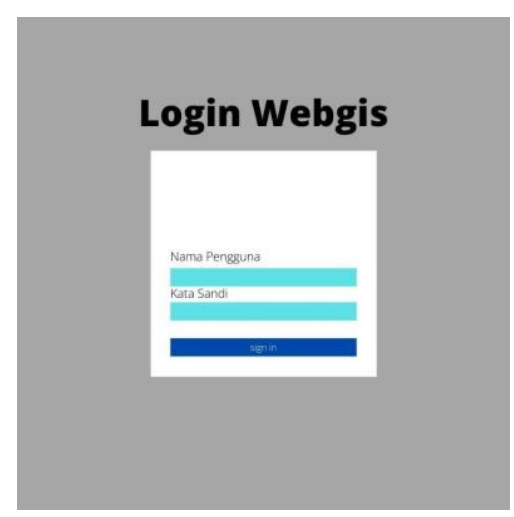

Gambar 5: Antarmuka Login 
Antarmuka login pada gambar 5, digunakan untuk mengakses dashboard dari sistem ini. Jadi sebelum mengakses dashboard sistem diperlukan login terlebih dahulu dengan username dan juga password yang sudah terdaftar oleh sistem. Apabila username atau password tidak sesuai dengan yang sudah terdaftar maka sistem akan menolak akses ke dashboard sistem.

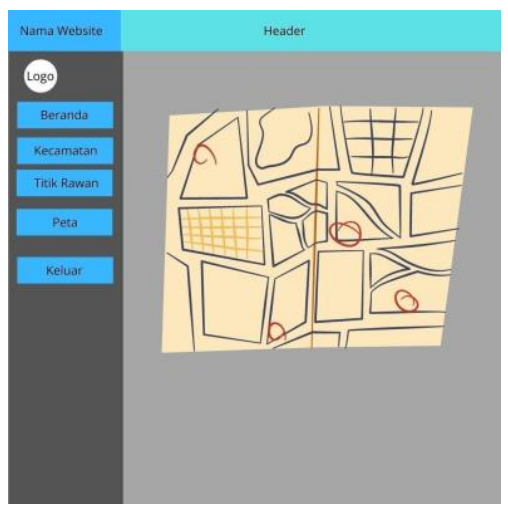

Gambar 6: Perancangan Interface Dasboard Admin

Gambar 6, menunjukkan halaman awal dashboard ketika membuka website, dijelaskan bahwa pada halaman awal akan langsung menampilkan informasi tentang peta kota Bandung.

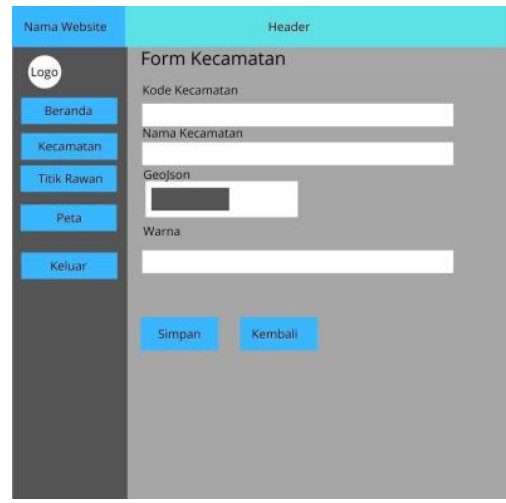

Gambar 7: Perancangan Interface Tambah Kecamatan Admin

Halaman tambah data kecamatan merupakan halaman untuk mengisi kelengkapan data untuk nantinya dimasukan ke dalam database. Halaman tambah data kecamatan ini hanya tersedia form untuk mengisi data serta tombol Simpan ketika data sudah selesai diisi. 


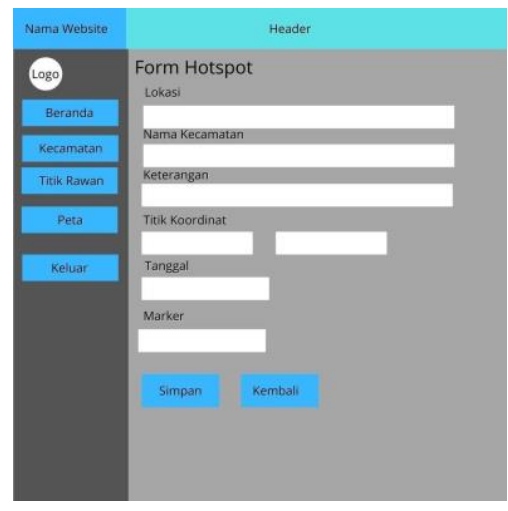

Gambar 8: Perancangan Interface Tambah Rawan Kriminalitas Admin

Halaman tambah data titik rawan kriminal merupakan halaman untuk mengisi kejadian kriminal yang nantinya dimasukan ke dalam database. Halaman tambah data kecamatan ini hanya tersedia form untuk mengisi data serta tombol Simpan ketika data sudah selesai diisi.

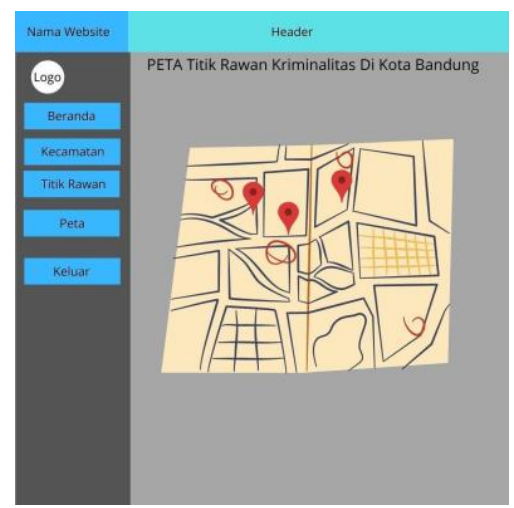

Gambar 9: Perancangan Peta Titik Rawan Admin

Halaman peta titik rawan kriminal merupakan halaman yang berisikan titik- titik kejadian yang telah di masukan datanya. Halaman titik rawan ini dapat memberikan informasi titik koordinat kejadian kriminal, alamat kejadian, tanggal kejadian, dan kronologi kejadian.

\subsection{Implementasi}

\section{Pengkodean}

Berdasarkan hasil rancangan yang sudah dibuat perlu diubah kedalam bentuk kode program agar menjadi sistem yang utuh. Pada tahap ini akan menghasilkan kode 
program yang sesuai pada rancangan yang sudah dibuat. Bahasa pemrogramman yang digunakan untuk membangun aplikasi ini adalah PHP DAN MySQL.Sistem yang dibangun merupakan WebGIS maka penulis menggunakan Leaflet Javascript Library sebagai pengolah data spasial kedalam bentuk peta.

Leaflet.Js (www.leafletjs.com) adalah open-source javascript library untuk membuat interactive maps. Library ini sangat populer karena mobile friendly, mempunyai ukuran file yang kecil dan dapat diextend dengan plugins ataupun dengan menggunakan fungsi javascript saja. Leaflet.Js dapat menampilkan peta/map dari berbagai sumber, seperti Google map, OpenStreetmap, OpenWheatherMap, dan lainlain(Vladimir Agafonkin, 2020).

\section{Keluaran Sistem}

Informasi yang dihasilkan sistem ini membantu masyarakat dalam memperoleh informasi kawasan rawan kriminalitas sehingga dapat mencari jalan alternatif untuk menghindari kawasan tersebut.

Sistem ini memiliki dua tampilan yang berbeda untuk admin dan user (masyarakat). Berikut adalah hasil dari penelitian.

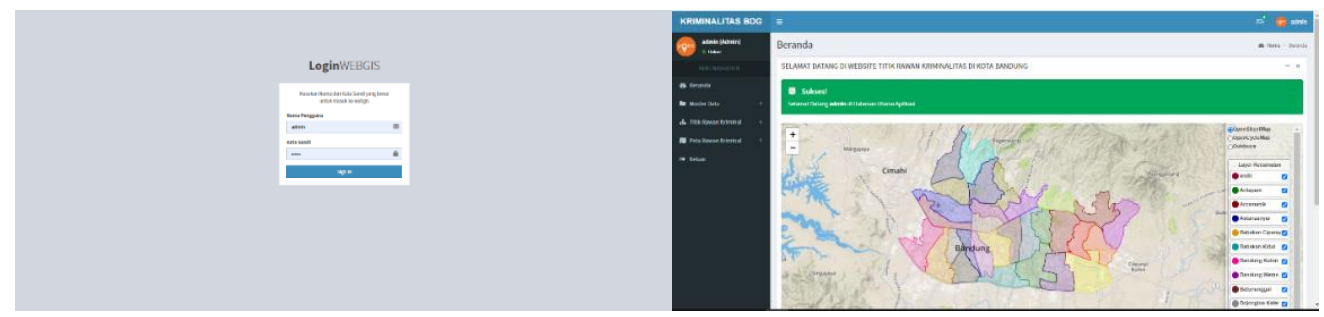

Gambar 10: Halaman login dan halaman depan admin

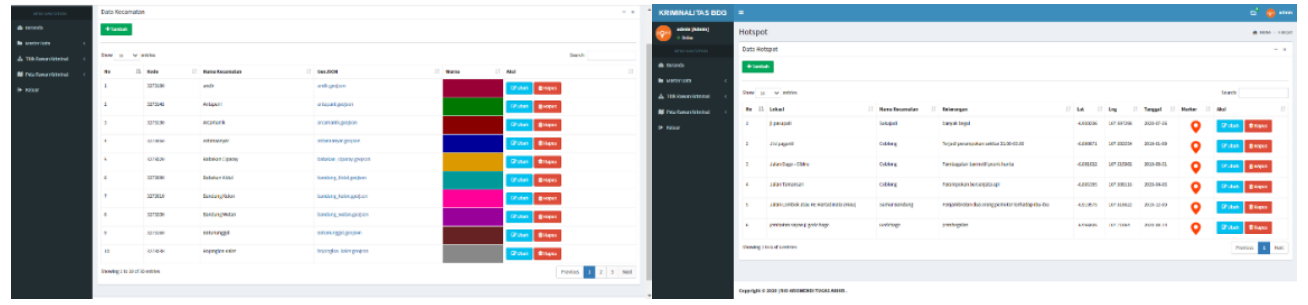

Gambar11: Halaman kecamatan dan halaman titik rawan 


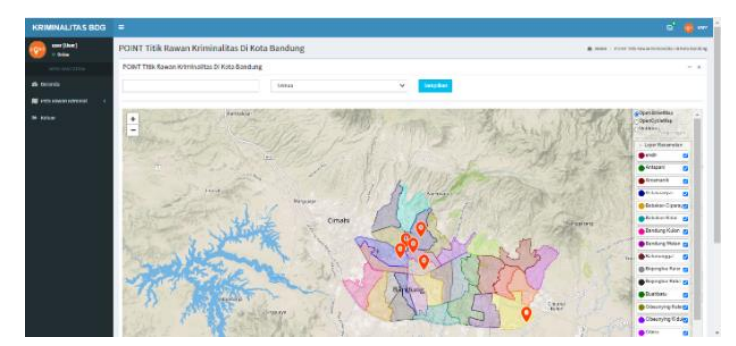

Gambar 12: Halaman Titik Rawan Kriminal

\section{Pengujian sistem}

Proses pada tahapan pengujian menggunakan metode Black-box, proses pengujian pada tahapan ini digunakan untuk mendapatkan kesalahan atau kekurangan yang mungkin terjadi pada software yang akan diuji. Black-box adalah pengujian yang fokus pada hasil sebagai respon input daripada berfokus pada mekanisme internal(Jaya, 2018). Proses pengujian akan memeriksa beberapa fungsional sistem seperti menambahkan, mengubah dan menghapus data dengan baik serta menampilkan peta pesebaran titik rawan kriminal.

Berikut disajikan beberapa contoh pengujian yang dilakukan dalam bentuk tabel:

Tabel 1. Pengujian perancangan Login

\begin{tabular}{|c|c|c|c|}
\hline Fungsi & $\begin{array}{l}\text { Tes yang di } \\
\text { lakukan }\end{array}$ & Hasil yang diharapkan & $\begin{array}{l}\text { Valid / } \\
\text { Invalid } \\
\end{array}$ \\
\hline \multirow[t]{6}{*}{ Login } & $\begin{array}{l}\text { Masukan Nama } \\
\text { Pengguna dan Kata } \\
\text { sandi } \\
\text { dengan benar } \\
\end{array}$ & $\begin{array}{l}\text { Menampilkan report } \\
\text { sukses }\end{array}$ & Valid \\
\hline & $\begin{array}{l}\text { Tidak mengisi Nama } \\
\text { Pengguna }\end{array}$ & $\begin{array}{l}\text { Menampilkan report kombinasi } \\
\text { pengguna dan kata sandi salah }\end{array}$ & Valid \\
\hline & $\begin{array}{l}\text { Tidak mengisi Kata } \\
\text { sandi }\end{array}$ & $\begin{array}{l}\text { Menampilkan report kombinasi } \\
\text { pengguna dan kata sandi salah }\end{array}$ & Valid \\
\hline & $\begin{array}{l}\text { Tidak mengisi Nama } \\
\text { Pengguna dan Kata } \\
\text { Sandi } \\
\text { pada }\end{array}$ & $\begin{array}{l}\text { Menampilkan report kombinasi } \\
\text { pengguna dan kata sandi salah }\end{array}$ & valid \\
\hline & $\begin{array}{l}\text { Masukan Nama } \\
\text { Pengguna benar, Kata } \\
\text { Sandi Salah }\end{array}$ & $\begin{array}{l}\text { Menampilkan report kombinasi } \\
\text { pengguna dan kata sandi salah }\end{array}$ & valid \\
\hline & $\begin{array}{l}\text { Masukan Nama } \\
\text { Pengguna salah, Kata } \\
\text { Sandi benar }\end{array}$ & $\begin{array}{l}\text { Menampilkan report kombinasi } \\
\text { pengguna dan kata sandi salah }\end{array}$ & valid \\
\hline
\end{tabular}


Tabel 2. Pengujian memasukkan data Kecamatan

\begin{tabular}{llll}
\hline Fungsi & $\begin{array}{l}\text { Tes yang } \\
\text { dilakukan }\end{array}$ & $\begin{array}{l}\text { Hasil yang di } \\
\text { harapkan }\end{array}$ & $\begin{array}{l}\text { Valid / } \\
\text { Invalid }\end{array}$ \\
\hline $\begin{array}{l}\text { Tambah } \\
\text { Kecamatan }\end{array}$ & $\begin{array}{l}\text { Mengisi semua data pada } \\
\text { form }\end{array}$ & $\begin{array}{l}\text { Menampilkan report } \\
\text { berhasil }\end{array}$ & Valid \\
\cline { 2 - 4 } & $\begin{array}{l}\text { Tidak mengisi } \\
\text { data pada form }\end{array}$ & $\begin{array}{l}\text { satu } \\
\text { Menampilkan validasi } \\
\text { data dan report data tidak } \\
\text { boleh kosong }\end{array}$ & Valid \\
\cline { 2 - 4 } & Tidak mengisi form & $\begin{array}{l}\text { Menampilkan report data } \\
\text { tidak boleh kosong }\end{array}$ & Valid \\
\hline
\end{tabular}

Tabel 3. Pengujian Tambah Data Titik Rawan

\begin{tabular}{|c|c|c|c|}
\hline Fungsi & Tes yang di lakukan & Hasil yang di harapkan & $\begin{array}{l}\text { Valid/ } \\
\text { Invalid }\end{array}$ \\
\hline \multirow{4}{*}{$\begin{array}{l}\text { Tambah } \\
\text { data Titik } \\
\text { Rawan }\end{array}$} & $\begin{array}{l}\text { Mengisi semua data dengan } \\
\text { benar }\end{array}$ & Menampilkan report sukses & Valid \\
\hline & $\begin{array}{l}\text { Menekan tombol simpan } \\
\text { apabila selesai } \\
\text { menambahkan data }\end{array}$ & Menampilkan report sukses & Valid \\
\hline & $\begin{array}{l}\text { Tidak mengisi salah satu } \\
\text { data pada form }\end{array}$ & $\begin{array}{l}\text { Menampilkan validasi data } \\
\text { dan report data tidak boleh } \\
\text { kosong }\end{array}$ & Valid \\
\hline & $\begin{array}{l}\text { Tidak mengisi data pada } \\
\text { form }\end{array}$ & $\begin{array}{l}\text { Menampilkan } \\
\text { report data tidak boleh } \\
\text { ksong }\end{array}$ & Valid \\
\hline
\end{tabular}

Tabel 4. Pengujian Lihat Peta Titik Rawan User

\begin{tabular}{llll}
\hline fungsi & Tes yang dilakukan & Hasil yang diharapkan & $\begin{array}{l}\text { Valid/ } \\
\text { invalid }\end{array}$ \\
\hline $\begin{array}{l}\text { Lihat } \\
\text { data }\end{array}$ & Menekan Peta Titik Rawan & $\begin{array}{l}\text { Menampilkan informasi } \\
\text { Titik Rawan }\end{array}$ & valid \\
Titik & & & \\
Rawan & & & \\
\hline
\end{tabular}

\section{SIMPULAN}

1. Sistem informasi geografis untuk Pemetaan Penyebaran Titik Rawan Kriminalitas Di Kota Bandung Menggunakan Leaflet Javascript Library Berbasis Website telah selesai dibuat dan berjalan sesuai yang diharapkan.

2. Sistem dibuat menggunakan library leaflet dapat dengan mudah dalam mencari informasi penyebaran titik rawan kriminal di kota Bandung dan masyarakat lebih 
mawas diri terhadap lingkungan di saat beraktivitas sehingga dapat selalu waspada terhadap siapapun yang ingin berbuat kejahatan .

\section{DAFTAR PUSTAKA}

Abdulloh, R. (2016). Easy \& Simple Web Programming. Jakarta: PT Elex Media Komputindo, 227.

Ambarwati, W., \& Johan, Y. (2016). Sejarah Dan Perkembangan Ilmu Pemetaan. Jurnal Enggano, 1(2), 80-82. https://doi.org/10.31186/jenggano.1.2.80-82

Andrianto, \& Jazman, M. (2018). Sistem Informasi Geografis Pemetaan Titik Lokasi Daerah Rawan Kriminalitas Kota Solok (Studi Kasus: Polres Solok Kota). Seminar Nasional Teknologi Informasi Komunikasi Dan Industri, O(0), 17-26.

Indrajani. (2015). Database Design (Case Study All in One). PT Elex Media Komputindo.

Jaya, T. S. (2018). Pengujian Aplikasi dengan Metode Blackbox Testing Boundary Value Analysis (Studi Kasus: Kantor Digital Politeknik Negeri Lampung). Jurnal Informatika Penge. Jurnal Informatika Pengembangan IT (JPIT), 3(2), 45-46. http://www.ejournal.poltektegal.ac.id/index.php/informatika/article/view/647/640

Kristanto, A. (2008). Perancangan Sistem Informasi dan Aplikasinya. Gaya Media.

Nelasari, C., Ramdani, F., \& Purnomo, W. (2019). Pengembangan Webgis Untuk Menentukan Jalur Aman Dari Kriminal Di Kota Malang Menggunakan Algoritme Bellman-Ford. 3(3), 2465-2471.

Portal Data Kota Bandung. (2015). Diskominfo. http://data.bandung.go.id/

R.S.Pressman. (2015). Rekayasa Perangkat Lunak: Pendekatan Praktisi Buku. In Yogyakarta: Andi (7th ed.). Yogyakarta Andi.

Vladimir Agafonkin. (2020). Leaflet an open-source JavaScript library for mobilefriendly interactive maps. Maps (c) OpenStreetMap. https://leafletjs.com/index.html 